\title{
A Theoretical Perspective on the Roles of Political Scientists in Policy Advisory Systems
}

\author{
Marleen Brans, Arco Timmermans, \\ and Athanassios Gouglas
}

\subsection{INTRODUCTION}

In this chapter we present a theoretical perspective for studying the policy advisory roles of political scientists. This is based on the concept of boundary work as developed originally by Gieryn (1983). Building on this and other conceptual work (Halligan, 1995; Weiss, 1979; Tenbensel, 2008),

M. Brans $(\triangle)$

Public Governance Institute, KU Leuven, Leuven, Belgium

e-mail: marleen.brans@kuleuven.be

A. Timmermans

Institute of Public Administration, Leiden University, Leiden, The Netherlands e-mail: a.timmermans@fgga.leidenuniv.nl

A. Gouglas

University of Essex, Essex, UK

e-mail: A.Gouglas@exeter.ac.uk

(C) The Author(s) 2022

M. Brans, A. Timmermans (eds.), The Advisory Roles of Political

Scientists in Europe, https://doi.org/10.1007/978-3-030-86005-9_2 
we propose a locational model of policy advisory systems, as a heuristic tool for mapping different actors within the policy advisory system of a country. The locational model consists of three spheres or arenas: the academic arena, the government arena, and the societal arena of external stakeholders and the wider public. Academic political scientists may be active at the intersections of the two arenas outside their own community. We also distinguish the main characteristics of policy advisory systems as the context of advisory relationships and activities.

In order to distinguish relationships and activities of individual academics engaging in advisory work, we construct a typology of advisory roles. This typology subsequently is used in a large pan-European survey among academic political scientists, of which the design will be presented in the next chapter. In Part II of this book, the contributors to this volume will analyse and discuss findings for their specific country and place these findings in the context of the policy advisory system. Political scientists may be located at different intersections between academia and the arenas of government and external stakeholders. They also may show caution in engaging in boundary work with these arenas. Section 2.2 introduces the policy advisory system as a context of orientation and activities of political scientists. The transfer of knowledge and advice within this policy advisory system is conceptualized in Sect. 2.3, and on this basis a typology of four different roles is presented in Sect. 2.4.

\subsection{Policy Advisory Systems}

To analyse and compare the advisory role of political scientists in policy making, it is necessary to understand what advice actually is, its nature and content, what are the underlying aspirations, aims and incentives for engaging in advising, and, as a context, which are the main properties of the policy advisory system in a country. While these elements of policy advising have not all been brought together in one theoretical or analytical framework, there are advances made in the literature that can help build such a comprehensive framework.

One body of knowledge focuses on 'policy advisory systems'. As Hustedt and Veit (2017) point out, the concept of 'policy advisory system' was first coined by Seymour-Ure (1987) and further developed by Halligan (1995) as an "interlocking set of advisory actors with a particular configuration that provides information, knowledge and recommendations for action to policymakers" (Halligan, 1995; Craft \& Howlett, 
2012). Advice in such systems flows from multiple sources, at times in intense competition with each other, with decision makers sitting in the middle of a complex web of advisory actors. Subsequent research on policy advice has focused attention on both the policy advisory system as a unit of analysis and on the activities of various actors involved in advising. Research focusing on actors shows growing attention to the specific activities they undertake, but most importantly looks at what determines the influence of advising actors within policy advisory systems (Colebatch et al., 2010; Craft \& Howlett, 2012). According to the starting hypothesis, influence in such systems is seen primarily as a combination of proximity to the policy maker and control of the advice delivered (Halligan, 1995). Increasingly it is also seen as contingent on the content of advice. What really matters in this perspective is not only location but primarily whether advice is 'cold', long term and anticipatory, or 'hot', short term and reactive (Craft \& Howlett, 2012). Furthermore, the idea is that it matters whether or not advice produces problem-solving statements (Hassenteufel \& Zittoun, 2017) suited to the views of policy makers on policy problems and solutions through the different stages of the policy cycle. Finally, the configuration of actors within the system itself is considered important.

Though research on this is still limited (Bossens et al., 2014), it appears that the configuration of actors in policy advisory systems varies between different institutional, political and epistemological traditions. Compared to other jurisdictions, Westminster policy advisory systems are seen to share a traditionally strong advisory role for the civil service, the expert composition of advisory bodies, and more receptiveness to management consultancy firms and think tank advocacy (Brans et al., 2017: 4-5). Some continental European countries as for instance the Netherlands may have come to share some of these features. Yet, the configuration of actors in the policy advisory systems in continental European countries generally displays more complex advisory relations, such as for instance in consensus style advisory bodies with mixed memberships of academics and representatives from civil society organizations. Also, management consultancy firms are seen to play a smaller role in advising governments, and think tanks are still an emerging discursive force in continental Europe (Ibid.). In some countries, especially of the Napoleonic administrative tradition, the policy advisory system is 'colonized' (Gouglas, 2018: 98) by ministerial cabinets that act as 'shadow administrations' (Brans \& Steen, 2007: 67). The work by Craft and Wilder (2017) on policy advisory networks 
within policy advisory systems is instructive to capture both differences between and within advisory systems. One example of this is variations of neo-corporatist advisory arrangements where civil society actors are prominent in advising government with or without the involvement of academics (Pattyn et al., 2019).

Another body of literature is on knowledge utilization. This literature originally had a narrower focus on relevant actors, in that it deals mainly with the science-policy-making nexus, and takes academic research as one source of advice in policy making. As Gieryn (1983) argued, demarcating science (research utilization) from non-science (more general knowledge utilization) is often difficult, and this demarcation and the 'boundary work between the two sides is a central part of these processes. This literature departed from a linear and direct model of knowledge utilization for policy making and moved towards the identification of different forms of knowledge utilization, including indirect and also symbolic ones (Weiss, 1979; for an overview see Blum \& Brans, 2017). The utilization of policy relevant information is seen as "a complex phenomenon involving environmental, organisational, and attitudinal components as well as the specific characteristics of information" (Oh, 1997: 6).

Inspired by the policy advisory system literature and extended to input from knowledge utilization research, Fig. 2.1 presents a revised locational model (Blum \& Brans, 2017) as a heuristic tool for studying variations in the advisory positions of academics. The model is composed of three arenas in which policy advisory actors are located and where policy advice is produced and flows towards other actors: the government arena, the academic arena, and the societal arena, in the latter of which also the wider public is located.

First, the three spheres are conceived as arenas, not as communities. The concept of arenas expresses that the production and consumption of policy advice is a process involving both 'puzzling' and 'powering' (Heclo, 1978). Earlier conceptualizations of policy advisory systems suggested a congruent relationship between advisory actors, by stating that sets of actors were interlocked. The concept of arenas as places where advisory actors may compete with each other and where advisory content may get contested serves not only to capture ideological and interest-based discordance within government and society; contestability is also more true to the nature of academic competition for claims to the truth.

Second, building on studies of knowledge utilization, the model is tweaked to study the advisory roles of academics, who have been largely 


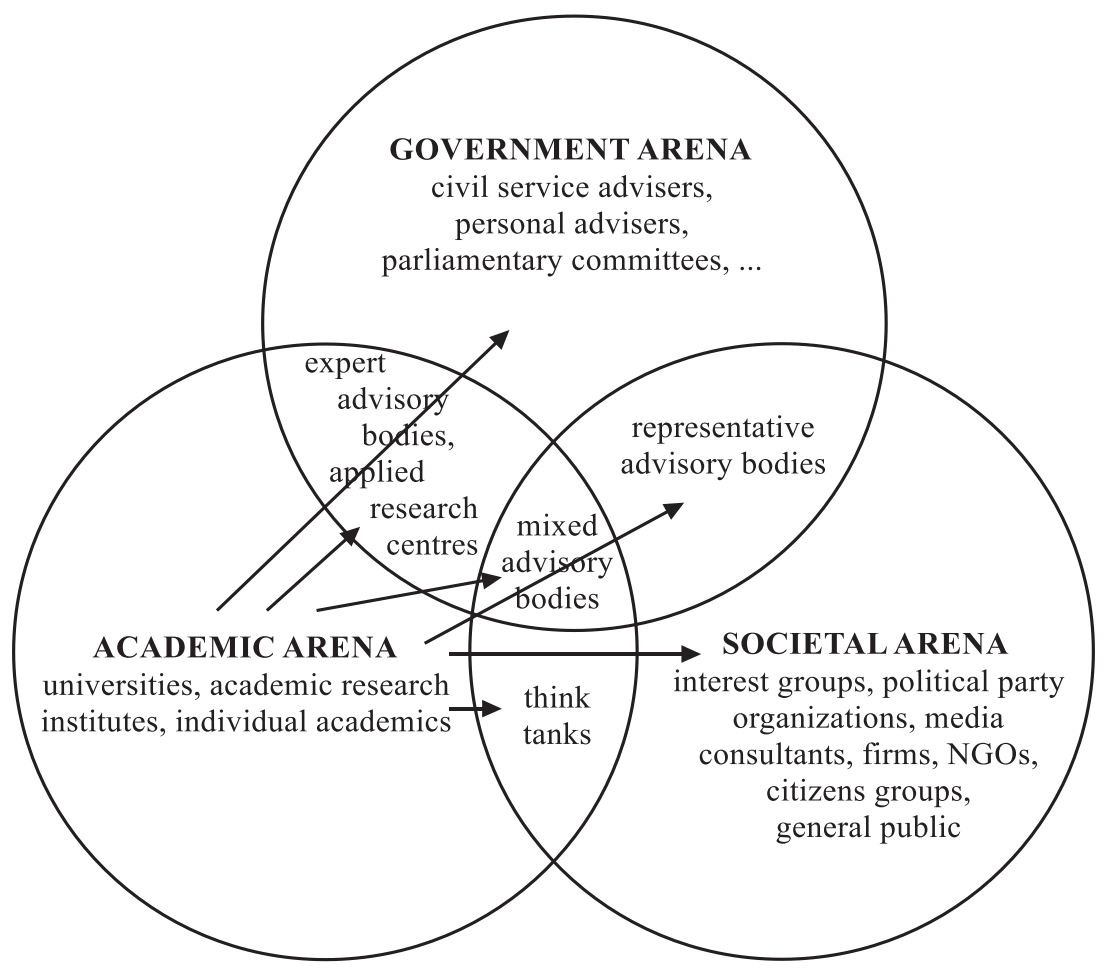

Fig. 2.1 Locational model of the policy advisory system. (Source: Adapted from Blum and Brans et al. (2017); Note: In its original conception the arenas were termed 'internal government arena', 'external academic arena', and 'external lay arena')

ignored in the literature on policy advisory systems, as for instance in Halligan's seminal article (1995) and in his work with Craft (Craft \& Halligan, 2020). The arrows indicate activity, noting that advisers working from the academic arena also have their basis of employment in it. This is to distinguish academics as advisers from all advisers in other arenas who have an academic degree but their actual employment within government or in any (semi)professional organization or group elsewhere. While this model may suggest that the academic arena is very prominent in volume and numbers, even equal in size to the other two arenas, this is done merely for stylistic reasons when visualizing the three arenas. In this model, 
within the government arena, the civil service is not the central actor, even though it is still both a producer and receiver of policy advice. Likewise, in the societal arena, in many professional organizations, knowledge and advice are both supplied and demanded. This may particularly be the case when institutionalized arrangements of governance exist that involve both government and public or semipublic organizations in policy making, as in (neo-) corporatist systems. Thus, the model can help to identify and pin down where, how, and why academic advisory activity occurs and is delivered in the other two arenas.

Third, the Venn diagram design of the model displays intersections of arenas as (often institutionalized) spaces for boundary work (Gieryn, 1983), in which advisory actors from two or more arenas produce advice that is meaningful to themselves and to actors in other arenas. The presentation permits us to conceive of differences between advisory locations where academics exchange knowledge and policy relevant information with government actors only, and other places where academics may be less involved or even excluded from advisory exchanges, such as in interestbased advisory bodies to government.

The locational model thus helps to characterize and analyse the policy advisory system of countries as a "configuration of advisory actors who exchange knowledge, information and recommendations for policymaking". In such a model, it can be indicated how access from advisory actors to the political-administrative and public spheres is institutionalized, to what degree interactions are channelled through structural interfaces linking research to governmental policy making. 'Locational' thus refers to the more or less structural positions and linkages of advising actors in the different arenas of the political-administrative-social system. While their home basis is the university, academics can and do enter the other locations where knowledge and advice is produced and used. This model enables analysts to compare and show similarities and differences between the policy advisory systems of countries. For the purpose of this book, it provides analytical leverage for presenting the positions of political scientists in the national advisory system, and considering for example the specific population density of political scientists within it compared to other kinds of actors (and academic disciplines) in advisory roles. It can help show how in some countries political scientists remain at a distance from other actors in the policy process, while in other countries the government and societal arenas are generally more open and accessible to input from political scientists working in academia. In some cases we find 
that political scientists populate the academic arena only and rarely venture into other arenas. In other cases, political scientists take up positions more numerously and structurally in other arenas, or are active at the intersections such as in think tanks or in policy advisory bodies and applied research institutes. They may even team up with consultants for contracted advisory work. Still in other cases, political scientists may stay away from civil society actors and focus their engagements mostly on political and administrative actors. Below, we deal with this variation when presenting different advisory roles.

Although it offers a useful start to map advisory actors and the locations for advisory exchange, the model is still a simplification. A policy advisory system is not static, certainly not in times when new actors make their way to the public arena, and knowledge and facts sometimes are discredited. The model offers a structural perspective of locating actors, but as is done here by the arrows drawn from the academic arena, the essence of it in practice is the dynamics taking place across the arenas. Moreover, the arenas and dynamics between them need not-and often are not-limited to the domestic level. As many processes in the social and economic reality, also policy making shows globalization-with tighter interlinkages between actors in governance, and also because policy problems became globalized (Pal, 2020).

In short, the reality of a domestic policy advisory system is dynamic, evolves, and is exposed to (or inviting) processes of internationalization of knowledge flows. For different purposes, the locational model can be adapted to include such advisory actors as in-house think tanks of international organizations such as the OECD, UN, or WHO, the Joint Research Centre of the European Commission or the European Parliament's Research Services, as well as international NGOs and think tanks operating at the global stage. Another use with wider geographical scope of the locational model would be to track and trace advisory activities of international academics whose policy relevant engagement travels far beyond the borders of the domestic policy advisory system of the country where their university is based. Such analysis could show an outside-transnationalroute towards the domestic advisory scene, where academic advice first reaches international organizations or NGOs and then trickles down to national arenas $(\mathrm{Pal}, 2020)$. One factor that may reinforce this territorial boundary crossing in policy advice is the internationalization of the scientific community itself. Political scientists have a strong international academic orientation. 
While such dynamic forces are at work, the policy advisory system in any country reflects the broader and deeper political-administrative social system within that country. At the macro level, a policy advisory system can, as the overall domestic system, be more (neo-)corporatist or pluralistic, show features of consensus or adversarial democracy, display moderate or intense partisan competition, have centralized or centralizing features, or rather tendencies of decentralization. Civic epistemologies, defined by Jasanoff (2011) as "institutionalized practices by which members of a given society test and deploy knowledge claims used as a basis for making collective choices" will also have explanatory power. These affect cultures of knowledge utilization and uptake, and will favour or disfavour instrumental rationality over political rationality. At the meso level, sectoral advisory systems are influenced by policy advisory styles (Aubin \& Brans, 2021 ), based on standard operating procedures for garnering policy advice within specific sectors. Policy advisory styles as they are rooted in a system may be open or closed to advisory input from non-governmental actors, or display short term reactive approaches to problem solving or be oriented on a long term and be more anticipatory. When looking at the specific advisory roles of academics, their place and activities within the advisory system will depend also on the self-understanding of disciplines and subdisciplines, more or less mediated by incentives and micro-level differences in motivations.

Two trends mentioned in the literature are externalization and politicization. While externalization as a concept used in the recent literature carries some bias as it takes the Westminster perspective of a prominent and neutral advisory role of the civil service as its point of departure (Hustedt \& Veit, 2017), it is a phenomenon visible in different types of political systems. Research done specifically on Westminster systems shows that, against the backdrop of declining civil service policy capacity, new advisory actors have come to populate advisory systems. Coupled with marketization, the externalization of policy advice has created fertile grounds for commercial consultant companies, particularly in countries such as the UK, New Zealand, Canada, and Australia (Saint-Martin, 2017). Furthermore, analysts see an entrenchment of partisan advisers in interfaces between ministers and their traditionally neutral civil servants (Diamond, 2020; Shaw \& Eichbaum, 2018). But also in consensus style democracies and variations of neo-corporatist systems, advice since long is produced by more external to government organizations, or in interfaces between government and civil society actors, with an involvement of 
interest-based organizations with representational monopolies in specific policy sectors. In such systems, the externalization trend is more towards a pluralistic advisory landscape in which new interest and advocacy groups enter the arena. Advice accordingly has become more competitive; regularly the value of academic expertise is contested against the value of socalled 'experience-based expertise', or lay expertise, or even against the 'wisdom of crowds' (Surrowiecki, 2004, quoted in Bekkers, 2014: 239).

Politicization is nothing new in countries where political advisers are since long firmly entrenched in ministerial offices that gatekeep policy advice from arenas internal and external to the government, thus maintaining the democratic chain of delegation. But as a contemporary trend, politicization is understood as a negative trend, signifying on the one hand the political instrumentalization of academic advice such as policy-based evidence-making (Straßheim \& Kettunen, 2014) and on the other hand 'fact-free policy-making' (Bekkers, 2014). Against this trend, but occurring more in professional, specialized and less public settings, is the rise of evidence-based policy-making. Here the call is actually resonating the scientification of politics which came in earlier decades with the growth of government to understand and address complex problems entering the agenda (Weingart, 1999). In the face of these trends of externalization, pluralization, and politicization, policy making thus is at best scienceinformed, with academic evidence as one source of advice next to experience-based practices and political judgement and opportunity that may take strong priority over knowledge and truth. With such a dynamic and changing context of advisory work, and forces that may also infringe on the nature of scientific advice itself, this is a point to consider more in depth the meaning of policy advice.

\subsection{What Is Policy Advice?}

Policy advising can be conceptualized as a communication process with four key elements: sender, message, channel, and receiver (Bossens et al., 2014: 3). Thus conceived, there are many types of senders, there also is a range of different receivers, and the message and channel can vary between institutional contexts, policy domains, and types of issue. Academics may take a role of sender of advice, but they are only one type of advisory actor within the policy advisory system. And political scientists are one group of academics that may engage in advisory activities or those whose work may have influence on policy making. The message is the policy advice itself, 
with specific content and form, and the channel pertains to publication and convocation modes. The recipients of policy advice are policymakers and other advisory actors in different arenas and intersections of arenas.

\subsubsection{Scope of Policy Advice}

Policy advice is about information that is considered policy relevant (Peters \& Barker, 1993). Depending on how much this information is processed by the sender, and on the interaction between the sender and receiver, this information is structured and presented more or less fully as advice about choice options for policymakers. Hence advice is usually described 'as aiming to support policy-makers' decision making by analysing policy problems and proposing solutions" (Halligan, 1998: 1686; Veselý 2017: 141). For this reason, policy advice often is related to the policy process, and largely, to policy formulation with an emphasis on the analysis of problems and the choice of feasible and acceptable solutions to these problems. Yet, policy advice not necessarily always provides a linkage or narrative between a problem and its solution: "Some advice defines a problem; some recommends a course of action to solve it" (Althaus, 2013: 5; quoted in Aubin \& Brans, 2021). While some advice evaluates ongoing policy piloting or considers past policies, other advice may be about setting the agenda or seek to demonstrate or downplay the urgency of a problem. Policy advice thus is not limited to the policy formulation and design stage. And importantly, advice can also refer to structures, procedures and rules, and even cultures of political and administrative organizations or the design of key elements of a political system, in what Sartori (1994) calls constitutional engineering. Specifically in political science, the object of advice may be what in other fields of social science (and moving also into the private sector) is called organization design (Mintzberg, 1983).

It can be hard to draw a clear line between a piece of advice and any type and portion of information that serves as input brought by knowledge producers into the policy process. Neither is advice, even when sent by researchers, always backed by scientific expertise: "Some advice is 'expert' expertise; most is not" (Althaus, 2013: 5). Advice often also has an experiential element, and much of what advisers do also can be driven by other motivations and beliefs. Further, a piece of advice can come in many formats. Policy advice be delivered as written statements in a research report, but it also can be a simple (but effective) text message, a communication in the social media, or a sentence spoken out in a conversation 
(Jones, 2003: 90). For this reason of variety in form, policy advice should not be defined by its form but by its function to give statements, proposals, arguments, frames and evidence that can contribute to solving problems (or to coping with them) at any stage of the policy cycle.

\subsubsection{Content of Advice}

Given the essential characteristics of the function of advice, the content can vary even more than the form. This is because, naturally, content of advice is specific to the matter or issue. With this endless variation in empirical content, it is useful to categorize content according to the type of knowledge contained in it. Drawing on Tenbensel's (2008) Aristotlebased typology of knowledge, we distinguish between three types of advice: (a) scientific advice (episteme) is about 'what is objectively true', (b) experiential advice (techne) is about what works in practice, and (c) practical value rationality (phronesis) is about what must be done (see also Flyvbjerg, 2001). These three types may include knowledge statements about facts, causal statements, predictive information, normative directions, evaluation of options, as well as technical and tactical advice (Hassenteufel \& Zittoun, 2017). With this range, advice produced by academics need not be limited to factual, causal, evaluative, and predictive knowledge statements, or in Tenbensel's terminology, episteme. It also can be technical (techne, 'what works') or normative (phronesis, 'what must be done'). This may lead to different types of advice, such as the provision of data and facts, analysis and explanations of causes and consequences of policy problems, evaluation of existing policies and functioning of institutions, giving recommendations on alternatives, forecasting and polling, and presenting value judgements and normative arguments.

This repertoire of advisory engagement can apply to any policy topic on the agenda. Advice can follow the political or public agenda, but the thrust of advice is also that it contributes to agenda setting (Timmermans \& Scholten, 2006). The notion of 'alarmed discovery' of an issue by scientists presented by Downs (1972) in his model of the issue attention cycle speaks to this effect. And it also is contained in the 'enlightenment' function of knowledge in Wittrock's (1991) models of interaction between social knowledge and public policy. As the design and evaluation of public policy (Lynn, 1981; Hall, 1993; Fischer, 1995), policy advice may happen at different levels, from the fundaments of a programme and its underlying paradigm to instrumental and operational aspects. Whatever is the 
causal direction between topics of advice and the policy agenda, the analysis of agenda setting over time shows clear differences in salience of policy topics and their sensitivity to drastic change. Comparative work on national executive agendas for example reveals that even despite wide differences between political systems, some topics such as the economy, international relations and the structure and operation of government often press heavily on the national political agenda, conditioning the space for topics such as the environment, migration, technology and education (Jennings et al., 2011). This conditionality of space for topics on the policy agenda also applies to the relationship between countries and international or supranational institutions, such as the EU (Breeman \& Timmermans, 2019). In short, the distribution of attention to topics in policy advising mostly is uneven, and large shifts can occur between topics over time.

\subsubsection{Channels of Advice}

While the content of advice may be its most distinguishing feature, it is also important to consider the channels through which advice is expressed and delivered. Lindquist (1990) suggests four main ways of communicating advice, building on distinctions in the direct or indirect nature of publication activities and convocation (or interaction) activities. He mentions (a) direct convocation activities, where advising actors discuss advice directly with the user, (b) indirect convocation activities, where the advice is transmitted indirectly through symposia or workshops, (c) direct publication activities such as memos and reports disseminated directly to the user, and (d) indirect publication activities, where advice is disseminated in intermediary bodies with the aim of influencing policy makers. To the traditional convocation activities social media may be added as a new and influential channel of communication. Given exposure levels, social media channels also are a new area of theoretical and empirical investigation.

Existing research indicates that it matters whether the nature of exchange is formal or informal (commissioned research, positions on advisory bodies or committee of inquiry, invitations to parliamentary committees versus informal networking, telephone calls). Further, it may be useful to distinguish between what Van Egmond et al. (2011) call 'front-stage presentation' and 'background processes'. While on the front-stage, academic policy advice may be expressed as objective and instrumental, in the background scientists and policy makers may be interacting informally, even about political-strategic issues. 
Defining policy advising as an exchange of knowledge, information and recommendations with policy makers and other stakeholders in the policy process implies a broad view on recipients of policy advice. Early conceptualizations of policy advisory systems placed civil servants at the receiving end of policy advice. While civil servants still are important recipients of academic advice, other recipients must be included, as they may be strongly involved or even be more important. Recipients of advice containing all kinds of knowledge statements are actors within specific arenas, and they also can be actors at the intersection of arenas: executive politicians, legislators, partisan advisers, civil servants, political parties, advisory bodies, think tanks, organizations with interests from the private, corporate sector, non-profit organizations, NGOs, civil society organizations, citizen groups, as well as international organizations. While the existing policy advisory system literature often focuses exclusively on the national level, it is useful to distinguish advisory activities also at the subnational and international or supranational level of governance.

\subsection{Advisory Roles of Academic POLITICAL SCIENTISTS}

The locational model is an analytical aid to capture a policy advisory system and place specific types of advising actors within it. In this book we focus entirely on political scientists as a community of academics. While advisers often have an academic background, those based at a university and thus belonging to a scholarly community must be distinguished from all other advisers with an academic degree but based in a different type of organization. It may be too drastic to call those other advisers professionals and academics amateurs in advising, but a key element is the locus of employment and primary affiliation. And when focusing on a scholarly community such as political scientists, the advisory roles seen and performed by them can vary.

The contributors to this volume together developed a typology of advisory roles, which is applied to the population of political scientists identified in the ProSEPS project. For this typology, we build on the relevant conceptual literature on scientists' policy roles. Pielke (2007) identified four types: the 'pure scientist', 'the science arbiter', the 'issue advocate', and the 'honest broker of policy alternatives'. The 'pure scientist' may share broad scientific knowledge and interpretations with policy makers, 
but takes no interest in the decision-making process. 'Science arbiters' provide consultancy services and stand by to answer factual questions, but do not tell decision makers what choices they should make. By contrast, 'issue advocates' lobby with decision makers for one alternative over others-they thus have more substantive stakes themselves. Finally, 'honest brokers of policy alternatives' supply comprehensive information about alternative choices for enabling decision makers to make their choices on better, evidence-based grounds. Another classification is suggested by Head (2015), who mentions four different groups of policy interested academics. The largest group consists of mainstream academics who, much like Pielke's pure scientists, if engaged, deliver broad interpretations and commentaries on policy and governance trends, but who generally stay at distance from practitioners. The second group is labelled expertcritics. They specialize in evidence-informed critiques of government policies in a particular policy sector. A third and small group-we may call them consultants - are those available for applied research services (such as programme evaluation) and technical advice (such as econometric modelling). Finally, academics may take secondments into advisory roles within public agencies or ministerial offices, and thereby become 'insiders' through their part-time roles in giving advice on policy options that meet the current needs of decision makers.

The various roles presented in the literature are a good starting point, but they lack elaboration. While the mainstream academic and the insider are useful and mutually exclusive types, the lines between the other types are harder to draw. Moreover, the criteria behind the construction of these types are not clear. What makes the difference? Is it the level of engagement, the type of advice or perhaps the specific location in the advisory system? Moreover, in the existing classifications, the pure and mainstream academic types do engage in an exchange of some kind of another, even when not very committing. For empirical research, we need one type that completely refrains from interaction with policy makers, and engages exclusively with colleagues within the scholarly community. If this group of scholars is visible professionally outside the academic arena at all, it will be in coverage of their research work by media taking an interest in their findings. In many countries, demonstrating relevance and impact potential after all also has become a criterion for fundamental scientific research funding (see Bandola-Gill et al., 2021).

For this reason, we distinguish four possible and generic roles that political scientists as a category of scholars may take. These are roles 
distinguished on the two most central dimensions of advising: (1) the type of advisory activity with its underlying knowledge orientation on episteme, techne or phronesis (Tenbensel, 2008), and (2) the frequency (or intensity) of this activity. They may co-vary, but they also may appear in different combinations. The two central dimensions we identify represent a chosen orientation and repertoire of activities in the policy advisory system of a country. We distinguish the pure academic, the expert, the opinionating scholar, and the public intellectual. Figure 2.2 presents these roles and their properties.

The pure academic is mostly dealing with fundamental science and does not engage with advice giving activities. If exposure happens, it is through media interest in the work of a scholar. But this exposure is not directly related to policy or institutional design for which advice is solicited or offered. It will more usually be placed as an item in the science sections or pages of newspapers, or be taken up when a major issue is displayed in the media and in its portrayal there is journalistic interest in scientific evidence for any claims made by stakeholders and policy entrepreneurs. Such media coverage is not frequent for most pure academics, and the content typically is limited to scientific expertise.

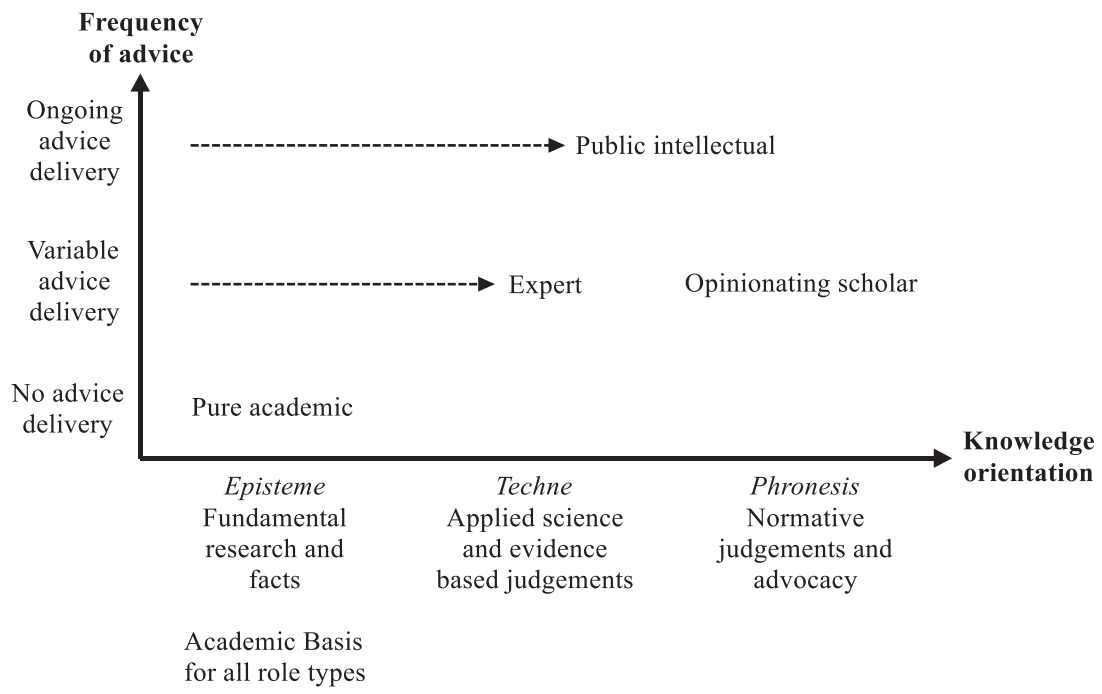

Fig. 2.2 A two-dimensional model of advisory roles. (Source: Author) 
A next step towards disclosure of knowledge and delivery would signify a scholar becomes an expert adviser, which is the second main type. The expert offers advice on a variable basis, formally and usually when requested by a recipient, most often one more directly involved in policy making. While we do not assume a very specific dedication here, expert advice will be provided to policy makers in the administration, committees, think tanks, and the content usually is based on empirical or applied research. Thus the knowledge types open up, involving techne, and consider what may work in practice. Episteme still underlies the evidence basis for the expert. As with pure academics, experts also may be visible in media and public arenas, and whenever this happens there is a stronger and more explicit connection made by the political scientist between a problem, what causes it and what ways appear for solving it. The expert role also may include interpretative work on demand in the media.

In our conceptualization and later on in this book when measuring the advisory role types, we consider advisory work and media exposure different spheres of activity. To some extent, media coverage of knowledge produced by academic political scientists may be related to the repertoire used for advising, but they also can appear separately. Hence media exposure as such is not included in the theoretically informed two-dimensional model of advisory roles. Whether busy advisory work of a scholar also comes often via media channels is an empirical question. This also depends on the media system (and the public sphere) of the country itself, and its place in relation to government and society. Expert advice usually will come in research papers, memos, reports, and so on. As with media exposure, we present our model of advisory types with no expectations on the channels and formats of delivery. They may be determined by strategy and technology as much as by the institutional set-up of policy advising.

The opinionating scholar displays a different orientation, with a stronger emphasis on interpretations, own viewpoints and normative positions next to facts as such. The opinionating scholar also takes the initiative for forwarding the advice or viewpoint. A strong opinionator has a high frequency and intensity of opinion giving. This may involve strong advocacy about a problem or solution, a way to go or conversely a disadvice brought with fervour. But opinionating scholars mostly are not pundits. The opinionating scholar is not per se more involved in advising compared to the expert, nor necessarily always more passionate about it, but is oriented more on the phronesis type of knowledge, about what should or should not be done. The role type includes cases where there is less deep 
engagement. It is the orientation and manifest activity of opinionating that distinguishes this role from a pure academic and an expert. While also the opinionating scholar has, as an academic, a basis in episteme, scientific knowledge often is not upfront in the opinionating activities.

Other dimensions of advising and engagement must be explored in how they become visible with the opinionating scholar. The various types of media are likely to be prominent in this role, and political science opinions may be delivered more often there than behind the closed doors of an advisory body. So the opinionator may use direct convocation activities, talk directly to targets or pursue a strategy of publishing op-ed articles, columns, blogs, and so on. We do not want to argue a priori that there are exclusive relationships between the opinionating role type and the exact channels, formal or informal ways and targets of this kind of activity. An expressive political scientist hired part time as a devil's advocate by the board of a government ministry to deliver strong viewpoints may be considered an opinionating scholar.

The fourth type of advising role is the public intellectual. This is a type, likely to be more exceptional to find, with a profile like a hybrid between the expert and the opinionator, and acting on both fronts with higher frequency. The public intellectual thus has the broadest combined repertoire of advisory and advocacy activities. With the university home basis and all related work as the epistemic fundament of the public intellectual, she or he may be also an opinion leader or a celebrated writer with a broader audience than colleagues who publish their findings only in peer reviewed journals. A true public intellectual political scientist may have one or more national or international bestsellers. In terms of name and fame, public intellectuals may be the ones at the top of the pyramid of engagement. They dispose of the skills and access points to deliver authoritative advice and opinions on political matters, and this is visible in the combination of types of activity developed with considerable frequency. Compared to very active experts or opinionating scholars, a public intellectual may not display the same intensity as either of these other roles types, but she or he generates external work in the two directions together more than any other type.

For using the typology of advisory roles of political scientists, it is crucial that the analyst takes a neutral stance towards any of the roles. This of course is generally important when linking theory and concepts to empirical inquiry, but it is particularly relevant here because the research project presented in this book is introspective: an international group of political 
scientists collaborating within the ProSEPS project analyses the policy advisory viewpoints and activities of their own peers in the scientific community. Thus, there is no normative point of departure in the study of advisory activities of political scientists in which one type would be preferred. This empirical study does not employ implicit or explicit evaluative standards of 'good' advice, 'appropriate channels' or 'justified positions and content', or conversely points to activities and content that bring political scientists into hazard or conflict of interest. Thus, more advisory activities are not a norm set against fewer or no such activities. The analysis focuses on the different roles and role perceptions of political scientists as they appear from the results of a large scale survey. They reflect viewpoints and behaviours reported by the respondents in the survey. Also a 'pure academic' has a role, while not in a direct entrepreneurial and politically or publicly serviceable way, but by more generally providing validated knowledge to the system at large rather than to any specific recipient or user. In Sweden and Germany for example, this autonomous, independent position is an important norm within the academic institutional arena. Also the often-made distinction between applied and fundamental knowledge does not separate utilized from non-utilized knowledge. Fundamental knowledge may be used, even if indirectly. Conversely, applied knowledge may remain unutilized, even when targeted to a specific user and or when a recipient solicited the advice in order to deal with an imminent problem.

Figure 2.3 places the four ideal types according to the arena in which they typically occur. Clearly, the public intellectual is the type mostly working across the boundaries of arenas - this type is a typical active boundary worker. The pure academic is the type least crossing boundaries. The academic arena not only is the home basis but also the 'comfort zone' of this type of political scientist. This model is locational and simplified, and it must be appreciated that, as argued above, pure academics may receive media coverage for their work, experts also may be orientated in part on the media and public arena, and opinionating scholars sometimes may be active within politics and the administration. Thus, the locations of the ideal types are not fully exclusive. When pure academics are visible in the media, however, they do not profile as advisers. Hence their remit is the academic arena.

The extent to which the four ideal role types occur is the central point of attention in the empirical analysis. The more or less institutionalized policy advisory system may facilitate one type more than another. Tenbensel (2008: 11) argues that knowledge orientations on episteme, techne, or 


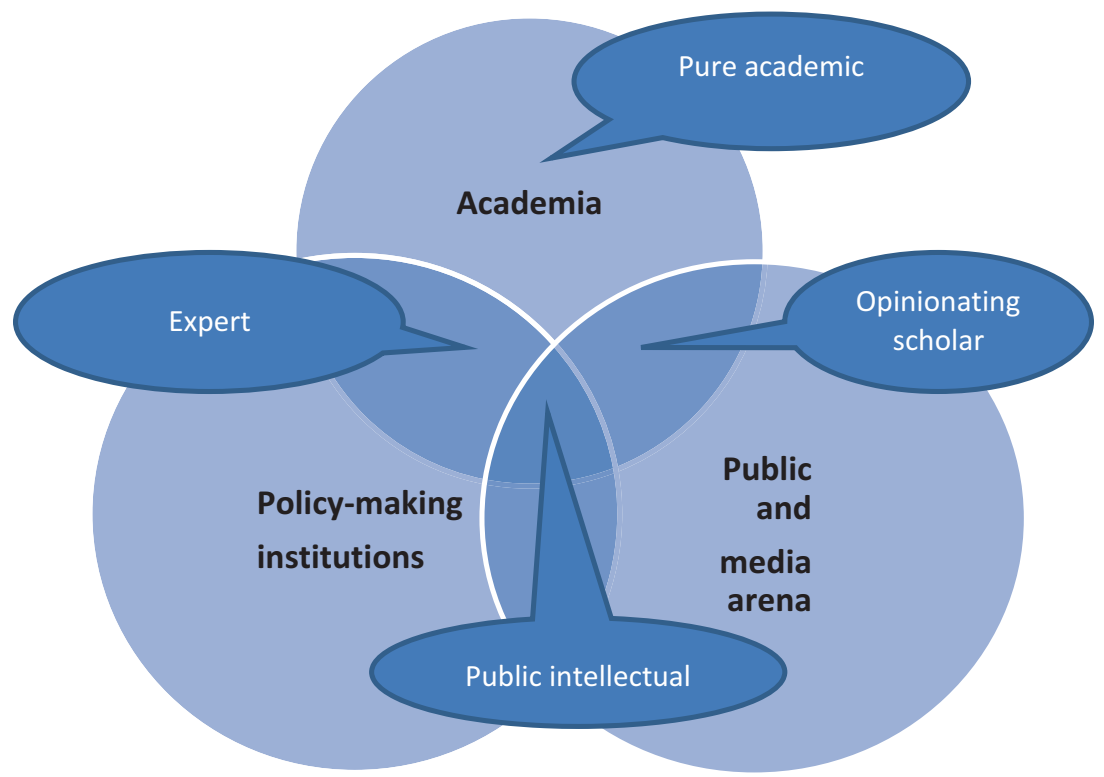

Fig. 2.3 Role types in the policy advisory system: political scientists as boundary workers. (Source: Author)

phronesis are likely to depend on the policy-making context, with emphasis either on hierarchy or on market forces or networked structures. Such variation may be observable between policy domains and particularly between countries, and it will become visible also in the types of advisory activities (or abstention from them). The policy advisory system itself also may be challenged and be in a process of alteration or even transition to which, in their various roles, political scientists may or may not contribute. Also the basic mode of governance within countries is not static. Hierarchies move to networked structures or to mechanisms of the market, or vice versa. Further, there are institutional factors within the university and within departments that may induce or impede political scientists to assume active roles bringing them into arenas outside academia. Finally, at the level of the individual political science scholar, normative views also may drive to advisory engagement or lead to abstention. For some, it is the way towards relevance and impact, but for others it may be a no-go area. 
In moving to empirical and comparative analysis of advisory roles in the next chapters, it is important to appreciate that this is done on the basis of the simple two-dimensional model of advising for categorizing political scientists. But as we saw, there are more dimensions of advice relating to channels, recipients, and subject matter. These are also analysed, supplementary to the categorization itself. The country chapters all employ this wide perspective on advising, while applying the simple model for comparative purposes. Further, to deepen the view on external roles played by political scientists, their individual characteristics are considered. Advisory role types not only may vary along the orientations on types of knowledge and frequency of engagement. They also may to a smaller or larger extent co-vary with gender, age, employment status, field of specialization and experience in practice oriented affiliations prior or during their academic appointment. In the final chapter of this book, we will draw together the main findings on these dimensions of advising and revisit the simple model. In this way, it is possible to progress from a theory-informed starting point to empirical comparative analysis and then back to the implications for theorizing on advisory roles of academics within the political science community.

\subsection{Conclusion}

This chapter presented the context in which academics as one-and special-group of policy advisers may take different roles towards policy makers and other stakeholders in the policy process. The institutional context in which interactions between academics and actors involved in the policy process happen is the policy advisory system. Thus far, the literature on policy advisory systems puts emphasis on institutional structures and design, and looks at trends at the macro level that may produce the flow of advice or alter it and bring new players into the arenas. Work on a specific group of advisers is more scare and focuses mostly on lawyers and economists (Christensen, 2015). Even rarer is analysis of academics and how they may perceive and take up advisory roles.

The perspective on policy advisory activities taken in this chapter and book is developed from the supply side. It looks at the way in which academics as one group of knowledge and information providers may see, behave, and experience incentives or impediments to taking an advisory role. We moved on to distinguishing four ideal typical roles of political scientists-generic ideal types based on a combination of concepts from 
the existing literature, with an empirical focus on political scientists. We have set a point of departure for empirically investigating advisory roles by constructing a simple two-dimensional model of advisory engagement. The idea here is that different orientations and activities, with their underlying knowledge types involved, must be linked to the frequency of activities in order to distinguish and identify the role types in practice.

A special feature of the scholarly community of political science is that the actors central in its object of study-politics and the policy processalso are the main recipient of advice. This gives Wildavksy's adagium 'speaking truth to power (1979)' a special meaning. In this book, the focus is entirely on the advisory part of the story. Whether 'power' takes and accepts this 'truth', uses it selectively or ignores it, is not part of our study. The extent to which knowledge or normative statements of political scientists get coupled to policy-making statements on what constitutes a policy problem, on how it should be solved, and in what possible direction (Blum, 2018) is a subject of study in its own right. Advice uptake is by no means a straightforward process, and however factual or scientific knowledge statements maybe, the very process of coupling these statements to policy action may range from instrumental use, to illumination and enlightenment to symbolic and political uses (Weiss, 1979; Head, 2017). For these reasons, we must be cautious with the distinction between supply and demand for advice, as political science advice may not always be solicited. While the role type of expert may signify demand, the role type of opinionating also may involve initiative or even advocacy from the side of political scientists. The distinction sender-receiver better captures the role situations in advising.

The contribution we make with this book and the perspective presented in this chapter directs the focus to a category of advisers, academic political scientists, which was not studied before in a systematic comparative way. We move on to presenting the way in which the simple two-dimensional model of advisory roles can be operationalized and measured in empirical research. Other dimensions of advisory work are included to produce a truly comprehensive view on advising routes and activities of political scientists. The design and criteria used for empirically mapping and characterizing advising roles of political scientists are the central theme of the next chapter. The contributors to the country chapters in Part II will apply the indicators and criteria and place advisory roles in their domestic context of the academic and policy advisory systems. In the final chapter we revisit the ideal types on the basis of country findings and overall patterns of advising. 


\section{REFERENCES}

Althaus, M. (2013). Reflections on advisory practice in politics. Political Science Applied, 1(2), 25-30.

Aubin, A., \& Brans, M. (2021). Styles of policy advice: A typology for comparing the standard operating procedures for the provision of policy advice. In M. Howlett \& J. Tonsun (Eds.), The Routledge handbook of policy styles (pp. 286-299). Routledge.

Bandola-Gill, J., Flinders, M. \& Brans, M. (2021). Incentives for impact: Relevance regimes through a cross-national perspective. In R. Eisfeld \& M. Flinders (Eds.), Political science in the shadow of the state: Research, relevance of deference. (pp. 35-63). Palgrave Macmillan.

Bekkers, V. (2014). Contested knowledge in theory-driven policy analysis: Setting the Dutch stage. In F. van Nispen \& P. Scholten (Eds.), Policy analysis in the Netherlands (pp. 231-247). Policy Press.

Blum, S. (2018). The multiple-streams framework and knowledge utilisation: Argumentative couplings of problem, policy, and politics issues. European Policy Analysis, 4(1), 94-117.

Blum, S., \& Brans, M. (2017). Academic policy analysis and research utilization for policymaking. In M. Brans, I. Geva-May, \& M. Howlett (Eds.), Handbook of comparative policy analysis (pp. 341-359). Routledge.

Bossens, N., Van Damme, J., \& Brans, M. (2014). Beleidsadvisering in de Vlaamse overheid. Een analyse van de organisatie van de Vlaamse beleidsadvisering en een verkenning van mogelijkheden voor optimalisering. Steunpunt Beleidsrelevant onderzoek.

Brans, M., Geva-May, I., \& Howlett, M. (2017). Policy analysis in comparative perspective: An introduction. In M. Brans, I. Geva-May, \& M. Howlett (Eds.), Handbook of comparative policy analysis (pp. 1-23). Routledge.

Brans, M., \& Steen, T. (2007). From incremental to copernican reform: Changes to the position and role of senior civil servants in the Belgian Federal Administration. In E. C. Page \& V. C. Wright (Eds.), From the active to the enabling state (pp. 63-80). Palgrave Macmillan.

Breeman, G., \& Timmermans, A. (2019). Horizontal and vertical attention dynamics: Environmental problems on executive policy agendas in EU member states. In F. R. Baumgartner, C. Breunig, \& E. Grossman (Eds.), Comparative policy agendas: Theory, tools, data. Oxford University Press.

Christensen, J. (2015). The power of economists within the state. Stanford University Press.

Colebatch, H. K., Hoppe, R., \& Noordegraaf, M. (2010). Working for policy. University Press. 
Craft, J., \& Halligan, J. (2020). Advising governments in the Westminster Tradition: Policy advisory systems in Australia, Britain, Canada and New Zealand (Cambridge studies in comparative public policy). Cambridge University Press.

Craft, J., \& Howlett, M. (2012). Policy formulation, governance shifts and policy influence: Location and content in policy advisory systems. Journal of Public Policy, 22 (pt 2).

Craft, J., \& Wilder, M. (2017). Catching a second wave: context and compatibility in advisory system dynamics. Policy Studies Journal, 45(1), 215-239.

Diamond, P. (2020). Externalization and politicization in policy advisory systems: A case study of contestable policy-making 2010-2015. Public Money \& Management, 40(1), 42-51.

Downs, A. (1972). Up and down with ecology. The issue attention cycle. The Public Interest, 28, 38-50.

Fischer, F. (1995). Evaluating public policy. Nelson Hall.

Flyvbjerg, B. (2001). Making social science matter. Cambridge University Press.

Gieryn, T. F. (1983). Boundary-work and the demarcation of science from nonscience: Strains and interests in professional ideologies of scientists. American Sociological Review, 48(6), 781-795.

Gouglas, A. (2018). Political advisers and circles of trust in Greek ministerial cabinets: Cardinals of the conclave, managers and the children of favouritism. In R. Shaw \& C. Eichbaum (Eds.), Minders and mandarins: An international study of relationships at the executive summit of parliamentary democracies. Edward / Elgar.

Hall, P. (1993). Policy paradigms, social learning, and the state. The case of economic policymaking in Britain. Comparative Politics, 25(3), 275-296.

Halligan, J. (1995). Policy advice and the public sector. In G. B. Peters \& D. T. Savoie (Eds.), Governance in a changing environment (pp. 138-172). McGill-Queen's University Press.

Halligan, J. (1998). Policy advice. International Encyclopedia of Public Policy and Administration, 3, 1686-1688.

Hassenteufel, P., \& Zittoun, P. (2017). From policy analytical styles to policymaking styles. In M. Brans, I. Geva-May, \& M. Howlett (Eds.), Handbook of comparative policy analysis (pp. 56-69). Routledge.

Head, B. (2015). Relationships between policy academics and public servants: Learning at a distance? Australian Journal of Public Administration, $74(1), 5-12$.

Head, B. (2017). Assessing the value of political science in the era of relevance and impact. Australian Journal of Political Science, 52(4), 599-614.

Heclo, H. (1978). Issue networks and the executive establishment. In A. King (Ed.), The new American political system (pp. 87-124). American Enterprise Institute. 
Hustedt, T., \& Veit, S. (2017). Policy advisory systems: Change dynamics and sources of variation. Policy Sciences, 50(1), 41-46.

Jasanoff, S. (2011). Designs on nature: Science and democracy in Europe and the United States. Princeton University Press.

Jennings, W., Bevan, S., \& Timmermans, A. (2011). Effects of the core functions of government on the diversity of executive agendas. Comparative Political Studies, 44(8), 1001-1030.

Jones, G. W. (2003). Book review: Guidance for governance: Comparing alternative sources of public policy advice by R. Kent Weaver and Paul B. Stares (eds.). International Public Management Journal, 6(1), 87-90.

Lindquist, E. A. (1990). The third community, policy inquiry, and social scientists. In S. Brooks \& A. G. Gagnon (Eds.), Social scientists, policy, and the state (pp. 21-51). Praeger.

Lynn, L. E. (1981). Managing the public's business. Basic Books.

Mintzberg, H. (1983). Structure in fives. Designing effective organizations. Prentice Hall.

Oh, C. H. (1997). Issues for new thinking of knowledge utilization: Introductory remarks. Knowledge and Policy: The International Journal of Knowledge Transfer and Utilization, 10(3), 3-10.

Pal, L. A. (2020). Twilight of hegemony: The T-20 and the defensive re-imagining of global order. In P. Dutkiewicz, T. Casier, \& J. A. Scholte (Eds.), Hegemony and world order: Reimagining power in global politics (pp. 148-163). Routledge.

Pattyn, V., Blum, S., Fobé, E., Pekar-Milicevic, M., \& Brans, M. (2019). Academic policy advice in consensus-seeking countries: The cases of Belgium and Germany. International Review of Administrative Sciences. https://doi. org/10.1177/0020852319878780

Peters, B. G., \& Barker, A. (1993). Advising West European governments: Inquiries, expertise and public policy. Edinburgh University Press.

Pielke, R. A. (2007). The honest broker: Making sense of science in policy and politics. Cambridge University Press.

Saint-Martin, D. (2017). Management consultancy and the varieties of capitalism. In M. Brans, I. Geva-May, \& M. Howlett (Eds.), Handbook of comparative policy analysis (pp. 213-228). Routledge.

Sartori, G. (1994). Comparative constitutional engineering: An inquiry into structures, incentives and outcomes. New York University Press.

Seymour-Ure, C. (1987). Institutionalization and informality in advisory systems. In W. Plowden (Ed.), Advising the rulers (pp. 175-184). Basil Blackwell.

Shaw, R., \& Eichbaum, C. (Eds.). (2018). Minders and mandarins: An international study of relationships at the executive summit of parliamentary democracies. Edward Elgar. 
Straßheim, H., \& Kettunen, P. (2014). When does evidence-based policy turn into policy-based evidence? Configurations, contexts and mechanisms. Evidence \& Policy, 10(2), 259-277.

Surrowiecki, J. (2004). The wisdom of crowds. Double Day.

Tenbensel, T. (2008). The role of evidence in policy: How the mix matters. Paper presented at the International Research Society for Public Management, Queensland University of Technology, 26-28 March, Brisbane, Australia.

Timmermans, A., \& Scholten, P. W. (2006). The political flow of wisdom. Science institutions as policy venues in the Netherlands. Journal of European Public Policy, 13(7), 1104-1118.

Van Egmond, S., Bekker, M., Bal, R., \& van der Grinten, T. (2011). Connecting evidence and policy: Bringing researchers and policy makers together for effective evidence-based health policy in the Netherlands: A case study. Evidence \& Policy, 7(1), 25-39.

Veselý, A. (2017). Policy Advice as Policy Work: A Conceptual Framework for Multi-level Analysis. Policy Sciences, 50(1), 139-154.

Weingart, P. (1999). Scientific expertise and political accountability. Paradoxes of science in politics. Science and Public Policy, 26(3), 151-161.

Weiss, C.H. (1979). The many meanings of research utilization. Public Administration Review, 39(5), 426-431.

Wildavsky, A. (1979). Speaking truth to power. The art and craft of policy analysis. Transaction Publishers.

Wittrock, B. (1991). Social knowledge and public policy. Eight models of interaction. In P. Wagner, C. H. Weiss, B. Wittrock, \& H. Wollmann (Eds.), Social sciences and modern states: National experiences and theoretical crossroads (pp. 337-339). Cambridge University Press.

Open Access This chapter is licensed under the terms of the Creative Commons Attribution 4.0 International License (http://creativecommons.org/licenses/ by $/ 4.0 /$ ), which permits use, sharing, adaptation, distribution and reproduction in any medium or format, as long as you give appropriate credit to the original author(s) and the source, provide a link to the Creative Commons licence and indicate if changes were made.

The images or other third party material in this chapter are included in the chapter's Creative Commons licence, unless indicated otherwise in a credit line to the material. If material is not included in the chapter's Creative Commons licence and your intended use is not permitted by statutory regulation or exceeds the permitted use, you will need to obtain permission directly from the copyright holder.

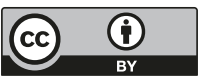

